\title{
PSYCHE
}

VOL. XXXVII

MARCH, 1930

No. 1

\section{THE FOOD OF INSECTS VIEWED FROM THE BIOLOGICAL AND HUMAN STANDPOINT ${ }^{1}$}

\section{By Charles T. Brues}

Our present-day views concerning human food and nutrition are in such a state of active revolution, that it may seem futile to discuss the food of insects on the basis of the fragmentary knowledge we possess concerning these small animals. I have avoided the term nutrition, however, since food relates to actual materials and does not necessarily introduce chemical and physiological connotations. It is, therefore, clear that "entomological chop suey" might more adequately, if less elegantly, express the content of my subject matter, provided, of course, that we first separate and accurately identify all the disguised components of this delicacy. This separation, and identification of insect foodstuffs has, as a matter of fact, been rather thoroughly done by entomologists and affords the basis for an understanding of at least some of the principles that underlie the trophic behavior of insects.

That these peculiarities have determined to a great extent the evolution and differentiation of insects is very clear, and as I hope to indicate later we must also attribute to them a very important role among the many factors that have directed the course of organic evolution since the time when insects became a dominant figure in the living world.

The most striking feature of the diet of insects is the high degree of specificity which exists in the selection of

${ }^{1}$ Presented by the retiring president at the annual meeting of the Entomological Society of America at Des Moines, Iowa, Dec. 28, 1929. Contribution from the Entomological Laboratory of the Bussey Institution, Harvard Uuiversity, No. 331. 
food by a very large percentage of the species. This is paralleled almost nowhere else in the animal or plant kingdoms, with the notable exception of certain parasitic organisms. In the case of these parasitic types, such as pathogenic bacteria, fungi and worms, it has of course never been questioned that they are important factors in influencing the abundance, distribution and, finally, the evolution of their hosts and of competing organisms. The same is self-evident with respect to parasitic insects, including those that carry diseases, and the recognition of the role played by entomophagous parasites has led to the development of the method of biological control that we have applied with success to the reduction of noxious insects. Such facts are so generally appreciated that we must not allow them to draw our attention at the present time from the less patent relationships that I wish to discuss.

The conventional classification of food habits as first applied to vertebrate animals, and later extended to other less familiar groups may be readily applied to insects and we may thus more or less accurately group them in the following categories which are by no means either clearcut or mutually exclusive, since they may grade into one another or appear in combination in the diet of a single species of insect.

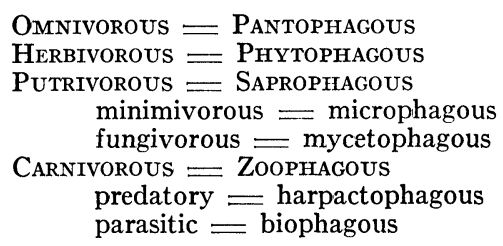

So far as insects are concerned it is difficult to arrange these in any linear order and certainly no single arrangement could be made which would indicate the phylogenetic sequence of the different types in the several major groups where they occur. Every type except the parasitic one is to be found among the most generalized groups of insects. Thus, the omnivorous cockroach, the vegetarian walking stick, or the predatory dragonfly are to-day emulating their forebears who feasted likewise in the forests of carboniferous times. 
It may seem idle to speculate concerning the most primitive type of food habits among the insects, although there seems good reason to believe that the earliest insects, like their somewhat problematical ancestors, may have subsisted upon dead or moribund animals in combination with miscellaneous plant material, or to speak more concisely, in terms of human dietetics, the balanced chop suey ration mentioned a few moments ago.

Such was undoubtedly the diet of the early multitudinous cockroaches that swarmed throughout those carboniferous forests. These very insects are today a prominent feature of the entomological fauna of tropical jungles, and, moreover, they have even invaded the overheated tenements of our great cities. The cockroaches, therefore, show three characteristic features: a mixed, more or less indiscriminate diet; great morphological stability over extended periods of time, and an adaptability to changing conditions and to intensive competition with other, more modern types of insects.

On the other hand, purely carnivorous habits are characteristic of several very primitive groups, notably of the earliest dragonflies. The predatory habits of these insects are very pronounced and predatism has attained a wonderful degree of perfection among the modern dragonflies. The imagines are admirably fitted for the capture of prey while on the wing, and the nymphs are even more marvelously adapted for the seizure of prey beneath the water in which they live. The mechanism peculiar to the nymph and unparalleled elsewhere is a unique, pincers-like, bristly organ, known as the mask formed by the highly modified labium. The form of this structure is so similar throughout the Odonata that there can be no doubt that it was characteristic of the earliest representatives of the order and perhaps of the ancestral Protodonata as well. So far then, as structural adaptation is concerned, the dragonflies must be rated very high. They have persisted over an extremely long period with little more tendency toward morphological change or speciation than the cockroaches. Even though the nymphal mouthparts are most exquisitely suited for the unfailing capture of prey, the diet of individual genera and species has not become highly specialized. We might 
almost say that the great efficacy of the mask has made unnecessary any great specialization in instinct; and, consequently, the diet of any species or individual varies greatly, depending upon circumstances. This statement is abundantly supported by observations made on the diet of dragonfly nymphs by several entomologists. These show that there is practically no selection since the imagines of a single species of dragonfly will devour a greatly diverse mixture of insects, while the nymphs consume also many small crustaceans, other invertebrates, and even some Protozoa.

Among the dragonflies, then, a long history with comparatively slow evolutionary change is associated with an indiscriminate diet during both the nymphal and reproductive stages.

If we now turn to certain predatory types among some of the more recent holometabolous insects we find a condition strikingly in contrast to that just described. In the Diptera, for example, there is a series of rather closely related families, that includes the robber-flies or Asilidæ, whose members are highly predaceous. Although only fragmentary data are available for these flies, some species are seen to have very strong predilections in the choice of prey. Thus, among the large flies of the genus Proctacanthus, one species captures almost entirely aculeate Hymenoptera, more than half of its prey consisting of honeybees and hornets, while the second greatly prefers small scarabæid beetles in combination with other miscellaneous insects. Other robberflies are butterfly hunters, but many are more or less general feeders, and a tabulation shows that, although there is a consistent choice of food among species, there is not the close restriction that prevails among parasitic insects, nor among vegetarian types which we will discuss in a moment.

A very high specificity in the selection of prey obtains among the solitary wasps. With these insects the prey is stung and stored in the nest, where it forms the food of the developing larva. Thus, the choice of food rests with the mother wasp, while the larva obediently eats what is put before it, thriving to maturity thereon. Although a very wide range of prey, including spiders and the most diverse irsects is utilized by these wasps, individual species com- 
monly restrict their hunting to the capture of a series of related forms or even to a single species. One American Aphilanthops stores only queen ants and a related European wasp captures ants also. Our common American muddauber wasps collect small spiders of various kinds and certain crabronids capture flies of a single or of several species. The fixity and persistence of their instincts is shown by the tendency of genera or larger groups to restrict themselves to related types of prey, and this may extend to the members of a large family like the Psammocharidæ, where the spider-storing habit is so general that the vernacular name of "spider wasps" has been bestowed upon them by common consent. In another group, stages through which the change from a somewhat indiscriminate diet to a specific one has taken place are still preserved. Thus, in the genus Sphex (Chlorion) some species store a variety of Orthoptera in their nests, others only a few, and finally some only one. As we shall see in a moment this condition prevailing among the solitary wasps is wholly analagous to that which obtains among phytophagous insects.

The tendency among these diverse types of predatory insects is clearly toward a restriction of the dietary although we cannot consistently detect any orderly arrangement whereby a relationship of predators implies to any great extent a similarity of prey. Sufficient evidence has been presented, however, to show that we cannot make any broad generalizations. Thus predaceous insects do not exhibit the close correlations characteristic of parasites nor of vegetarian insects. At this point, we must emphasize the fact that many predatory insects have narrowed down their food relations to a point where their direct contacts with the environment are restricted to certain definite components of the fauna of which they themselves form an integral part. The significance of these facts may be best understood after we have examined the food relations of vegetarian insects.

Insects that feed on plants are far and away the most important series to illustrate the adherence of species or larger groups to restrict diet. On account of their complex relationships toward these plants directly, and indirectly 
through them to other animals, coupled with their great abundance and diversity, they are of extreme interest. Their ecological relations are far reaching for they extend, tentacle-like, into the innermost corners of every type of terrestrial, aerial, or fresh-water environment. From the general biological or evolutionary standpoint they are of peculiar interest for it is this vast horde of vegetarian species (for they include about half of the living kinds of insects) that have made their influence felt over the long lapse of geological time since these types became highly differentiated during the periods preceding the tertiary. The chronology of this process, at least with regard to specific food relations, is difficult to determine, but taxonomic groups similar to those of today were so well established in the eocene and oligocene that we can rest assured that their food relations were already equally complex at that time. Thus, the time during which the factors introduced by these insects have been active in affecting the evolution of other animals and plants is much more extended than that included in the period just mentioned. As I have shown previously, there is good reason to believe that the differentiation of feeding habits among phytophagous Coleoptera was well under way while that of the Lepidoptera was just beginning at the time when the modern types of trees appeared on the earth.

There is no need to attempt at the present time any detailed account of the specificity of food selection among the Lepidoptera as this is well known and I have already dealt extensively with it elsewhere. Briefly, we may say that the members of this order may be considered as forming two or three groups with respect to specificity of food. These are: first, those which utilize a very considerable and not necessarily related series of food plants, occasionally a hundred or more in number, like the cecropia moth or the leopard moth; second, those having a much more restricted dietary that includes a few, usually related, species; and finally, some that are confined to a single plant host or to several very closely related and genetically similar members of a single genus. Again, these categorical divisions are only relative; but experience shows them to be very convenient, and we may unquestionably regard them as successive phylogenetic stages. We may conveniently refer to 
the insects concerned as polyphagous, oligophagous and monophagous, respectively.

The labors of economic entomologists have gone far toward an elucidation of the interactions of these several types of food-habits as they determine the competition for food among insects and the devious ways in which they influence the biocœnotic relations of insect food plants. And, since no plants appear to be immune to insect attack this question is seen at once to involve the whole terrestrial flora.

Several factors concerned in these relationships between insects and plants may be considered separately. The effect of insect feeding on the flora is by no means the same in the case of polyphagous, oligophagous and monophagous species. With the former a long series of plants suffer to a more or less equal degree. Thus, with grasshopper outbreaks there is general injury to all kinds of vegetation; with the gypsy moth a considerable series of trees and also other plants suffer, but not to an equal extent. This means that there is a simultaneous reduction in the abundance of a number of different plants, and an opportunity is offered for many others to increase, at least temporarily, while many competing insects decline due to a lessened food supply. Thus, in brief, outbreaks or fluctuations among polyphagous species involve many other insects and plants to a major extent. We can also see how such feeding might actually cause the extinction of certain rare or poorly adapted plants.

The feeding of oligophagous insects results in the injury to a greatly restricted series of plants and has, of course, no direct effect upon any others. If dominant species of plants be affected there as a very considerable opportunity for many rarer forms to increase, while if a reverse condition prevails and the scarcer forms are affected, the influence upon the remainder of the competing flora is negligible. Incidentally we must notice that the extinction of certain plants might result from the feeding of oligophagous species, although the chances for such an occurrence are less than those noted above in the case of polyphagous insects since a great reduction in one of a few food plants will at once considerably reduce the food supply. This is then immediately reflected in a lesser abundance of the in- 
sect, and injury decreases. In general, therefore, the feeding of oligophagous insects does not involve simultaneous fluctuations in a considerable number of plants, especially if those concerned are not dominant forms, and likewise, a smaller number of species of insects is affected directly. The fluctuations that may occur among associated insects are to a greater extent in an inverse ratio rather than in a direct one.

Monophagous species present a very remarkable series of phenomena. Aside from any parasites they may support or predators that they may feed, their relations to the living environment are entirely restricted to contacts through the medium of the host plant. They can never become so abundant as to rise up and destroy it, since for obvious reasons their fluctuations in abundance trail very closely those of their host plants. Therefore, we may never attribute the extinction of any plant, even in a restricted region, exclusively to the activities of a monophagous insect. Other plants are affected to a varying extent, dependent mainly upon the rarity or abundance of the host plant. If it be a dominant species, its fluctuations increase or decrease the struggle for existence among competing plants; if it be a rare species, this influence upon a series of other plants is negligible. It also affects a number of associated insects which feed upon the same food plant. The number of these is, of course, extremely variable, but careful studies of plant faunæ indicate that dominant types of plants support surprisingly large numbers of vegetarian insects mounting into hundreds of species in the case of common types such as willows, figs, oaks and maize, although the average for plants in general falls far below this mark. Certain plants which produce poisons or violently irritating substances, (like our common American poison-ivy), enjoy comparative, but by no means complete immunity from injury by phytophagous insects.

In regard to their relations with the living environment, we may say that monophagous insects live a life apart. Their association with plants is such that the vicissitudes of life for both members of the pair are greatly reduced on account of the lesser number of variable factors that affect each. So far as abundance of fluctuation in numbers they 
are mutually adaptive. The instincts determining food selection are firmly fixed in the germ-plasm and the insect is doomed to feed to the end of its days on beans, cabbage, yeast or what-not, unless some fortunate shift or mutation of instinct may add pork to the beans, or perchance combine hops and malt with the yeast ration. Such persistence over long periods during which whole groups of insects and plants have evolved in mutual adaptation seem only to be explained on the basis of instinctive behavior. This view which I have upheld in the past has been recently questioned by some, who would place the matter upon a purely physiological basis, but I cannot see that there is convincing evidence to support this conclusion or to controvert my own contentions that we are dealing with persistent instincts rather than with digestive necessities.

With the foregoing considerations on phytophagous insects as a basis it is possible to draw certain conclusions of a general nature which indicate some of the ways in which the development of oligophagy and monophagy has influenced the evolution of the higher plants as well as that of the insects themselves. Due to its tendency to reduce the chances of extinction of plant species whose existence might be jeopardized by an abundance of polyphagous insects we can see that it has tended to increase the diversity of the flora. The development of many mutual adaptations of plants with both monophagous and oligophagous insects are dependent upon the specific food habits of the insects concerned and it is thus clear that we must attribute to the development of these instincts many of the remarkable morphological modifications seen in both plants and insects. In the present state of our knowledge, at least, there is no other causal explanation for their existence. Since speciation and the rapidity of evolutionary change in general are highly correlated with adaptive modifications, we must attribute to the phenomena of restricted food a highly important role in determining the trend of these evolutionary processes.

A relationship similar to the one just given was early noticed by Darwin in connection with anthophilous insects and entomophilous flowers and his interpretation of the mutual modifications of insects and flowers has long since 
become solidly entrenched among the unassailable biological doctrines, after having further engaged the attention of a score of later naturalists. I mention it here not for discussion, but only to show the similarity to to views just expressed concerning phytophagous insects and their foodplants.

Really no time remains for the discussion of the other types of food habits among insects which I had hoped to mention in connection with their biological interest. They would serve to clarify the statements already made, but since they might also cloud the issue somewhat and since they show how thoroughly the insects have exploited the world's food supply they are more appropriately dealt with in connection with my concluding remarks on insect food as viewed from the human standpoint.

From a purely human standpoint, we must regard everything as either beneficial or harmful, unless it appear to be utterly unimportant or indifferent and the scientific mind will not admit the third possiblity. As entomologists are prone to look upon insects in this light we may view them thus at the moment.

\section{INJURIOUS INSECTS}

harmful to man directly harmful to useful plants harmful to useful animals

a. harmful to useful insects

\section{BeNEFICIAL INSECTS}
destroyers of injurious insects destroyers of undesirable plants destroyers of obnoxious substances producers of useful substances.

I think this classification reflects the usual attitude toward the economic relations of insects, and it serves well to emphasize the fact that the importance of every species is gauged by what it harms, injures or destroys, with the sole exception of the small handful of "producers" like the 
honey bee, silkworm, etc. This can only mean that, practically, the activities of insects that appear to be of greatest human interest, are those which serve to destroy other things. As the ultimate purpose of the human species is to destroy and make over the face of nature, quite naturally insects and man are at once both in accord and conflict, and our most competent practical entomologists predict a battle to the death between insects and man. Unfortunately for ourselves, man has proceeded to change the face of nature as rapidly and completely as possible. In so doing, he has found his progress seriously impeded by an unforseen increase in the numbers of insects that feed upon agricultural, horticultural and forest crops, combined with an equally unexpected migration or spread of many phytophagous species into regions where they did not previously occur. There is no need to press this point for we all realize that this is a serious situation that confronts agriculture, horticulture and forestry today. It is equally clear that this distressing condition has been brought about mainly by two factors inherent in our prevailing mode and philosophy of life. One is the growing tendency throughout the world, and particularly in America, to devote more and more extensive areas to the propagation of easily managed crops that give promise of large pecuniary returns. This matter then goes deep into the fabric of our commercial life. The other factor concerned is the unprecedented increase in the bulk and variety of vegetables, fruits and food-stuffs of all kinds that are shipped here and there in all directions, aften to the uttermost corners of the earth wherever they may be disposed of at a profit. If, as generally occurs, there is great local over-production of certain foods, the urge for wider distributional opportunities is so powerful that it must needs invoke the aid of advertising propaganda and every other known method that may be put to the tune of modern jazz. No one has ever suggested the curtailment of such shipping on economic grounds. This matter is, of course, likewise not a suitable subject for unbiased discussion except in purely academic circles, since it is too deeply concerned with the business of transportation, with advertising, with the love of luxury and with other matters of vast and immediate pecuniary importance. 
Having thus bared a very pessimistic attitude and exposed to view what you have doubtless recognized as the clear, clinical picture of an inferiority complex, let us return to some purely entomological phases of the matter. How do the several types of food-habits among vegetarian insects affect their pracitical importance in relation to the human food supply? It is generally conceded that monophagous and oligophagous types are the ones most destructive to cultivated crops. We can at once recall a long series of such species, the potato-beetle, the codling moth, the oriental peach moth, and many others whose importance is due to the fact that they unerringly pick out valuable and widely cultivated agricultural plants. On the other hand, many with a considerable range of food-plants, the bollworm, the corn-borer, the Mediterranean fruit fly, the melon aphid, the red scale and the like are very destructive, but quite generally less so on the whole, in spite of the much greater variety which may feed upon a particular species of plant. General feeders like the various types of locusts, army worms, etc., although very conspicuously destructive in some regions and on certain occasions, are in the long run less generally dreaded by agriculturists. To return then to our earlier discussion of monophagy and oligophagy, we must admit, without further ado, that our present civilization could well dispense with this interesting evolutionary phenomenon, since it is a gift of Nature that serves to increase injury to cultivated plants, at least under modern agricultural conditions. We might return the gift with thanks, but so far, science has been unable to write a sufficiently polite or forceful note to accompany the transfer.

There is just one more matter relating to these destructive insects which I hesitate to mention as it is so familiar to all of us. It was one of the first choice bits of information we acquired as students and we have religiously passed it on to our students ever since. The most destructive insect pests are those that have spread from their original habitat into some other faunal region. The reasons for this are usually said to be well understood on the basis of predatory and parasitic control, but there is much to suggest that other factors remain still to be elucidated. 
Since human behavior is conventionally regulated by prohibitions, punishments and legislative action of endless variety, it is quite natural that the immigration of insects should have come to the attention of law-makers as a fit subject for similarly paternal consideration. The protection of the human population from communicable diseases by restricting the movements of diseased persons has been so satisfactorily effected by quarantine measures that excludatory regulations have been instituted to protect countries from invasion by insects from other regions, without a clear statement that the two situations are neither identical nor essentially similar. Thus, such regulations have been based upon the inspection of host plants or other materials. The success of these has not been all that might have been hoped and there is a wide divergence of opinion as to whether the results attained are in any sense commensurate with the great expense and hardships entailed. It is quite clear that the absolute exclusion of insects is a much more difficult undertaking than the interception of cases of human disease. Human beings are dealt with legally and otherwise as individuals and besides, the success of public health measures does not depend upon absolute exclusion for all time. There is no question that such measures must aid somewhat to delay the introduction of insect pests where some natural geographical barrier to animal or plant migration exists. As time goes on, as transportation increases and speeds up and as movement becomes our main interest; the poor old oceans, mountains and deserts are rapidly losing their importance as separating faunas and floras. In our own country during the past few years there has also been an increasing movement to prevent the spread of particular species of insects between states or other artificially limited areas where absolutely no natural barriers exist. This in itself is a most commendable endeavor when it can be carried on unostentatiously and at reasonable expenditure, since it serves to delay the otherwise extremely rapid naturalization of insects over contiguous areas. In some instances it is obvious that such quarantines may become oppressive and entail expenditures and economic consequences to communities that are not at all warranted by any advantages that might reasonably be expected to accrue 
from them. This is well illustrated by the supreme efforts made to curb the spread of the Mediterranean fruit fly following the recent discovery of its establishment in Florida. Many persons were even led to believe that the extermination of this pest in the United States was a foregone conclusion instead of a hoped-for miracle. Certainly long experience in connection with the establishment of exotic insect pests of cultivated plants holds out little prospect of their eradication. Another unfortunate circumstance in this connection is the great menace of repeated introductions of the same insect. I do not wish to pose as a critic of the legislative activities of entomologists but feel that it is our duty to view such matters in an unbiased attitude and to shy clear of the idea that all evils may be remedied by the enactment of laws and the expenditure of money. The use of the quarantine has increased at such a rapid rate that we should be sure of our ground before allowing it to usurp the foreground of entomological practice. Another grave danger lies in the fact that perfectly sane scientific pronouncements may be easily perverted by legislative enactment and subsequent enforcement by persons far less expert than the entomological authorities who formulated them.

Certainly the importance of these problems and the threat which they hold over our future comfort and welfare demand that we as entomologists approach them in an altruistic spirit. 

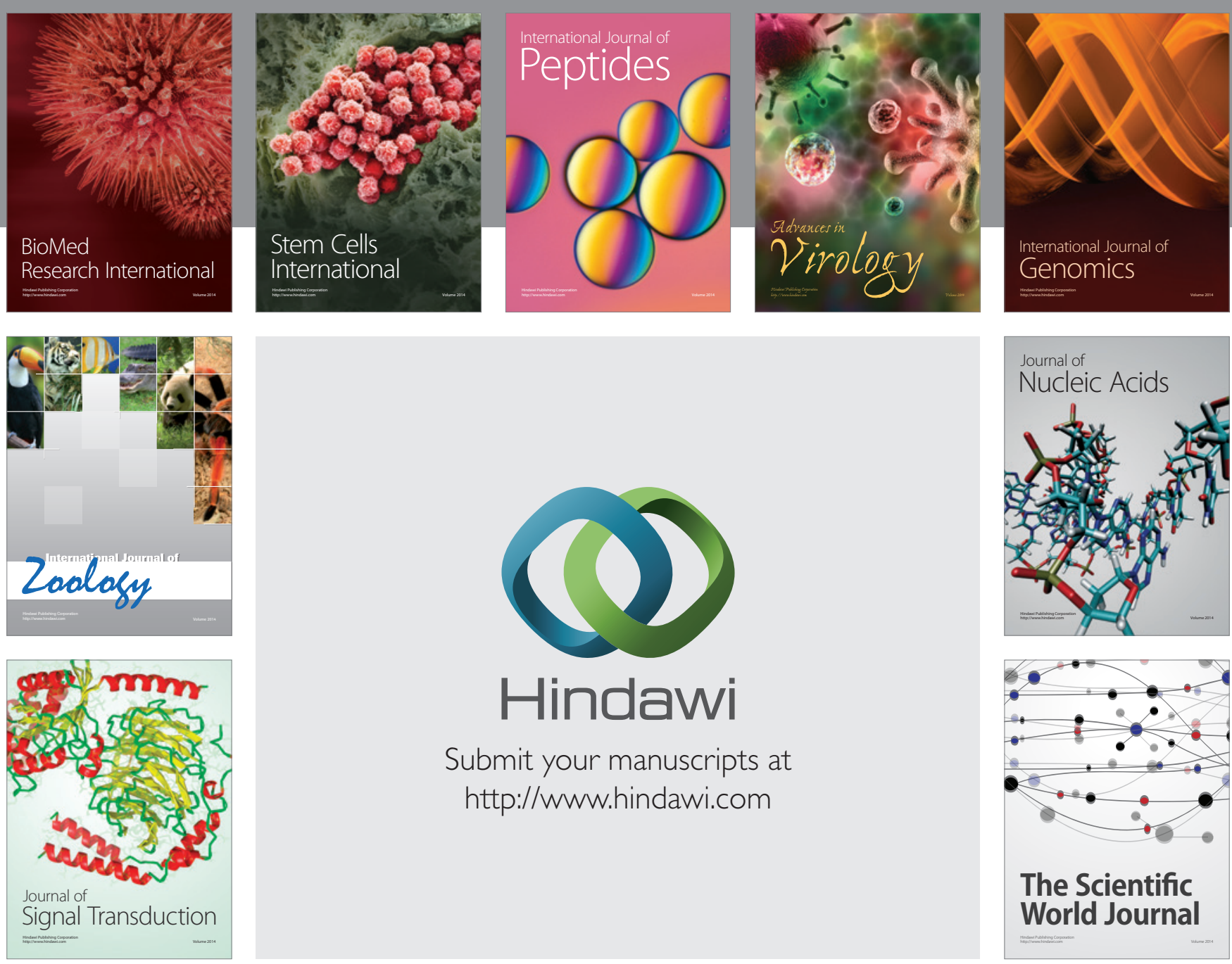

Submit your manuscripts at

http://www.hindawi.com
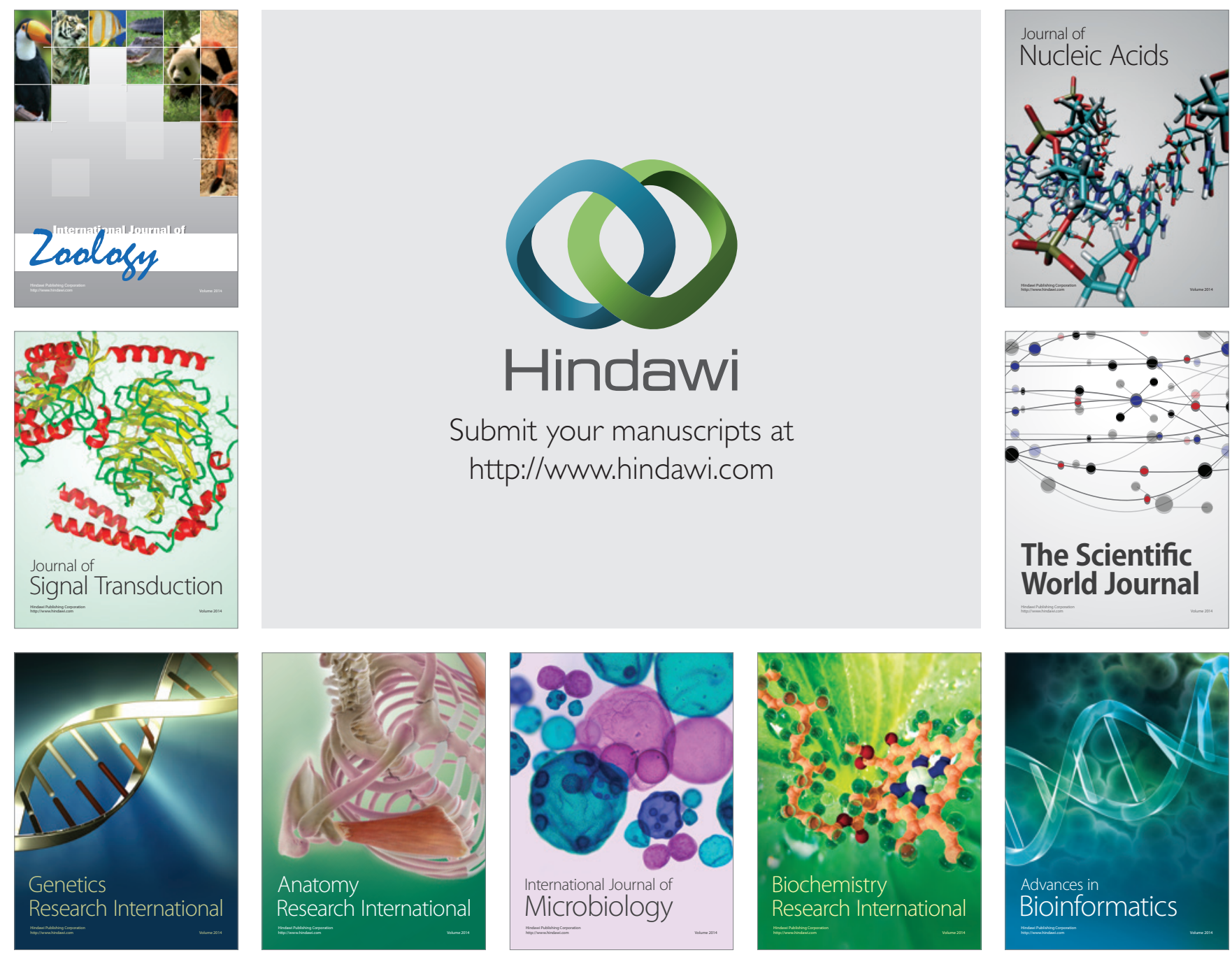

The Scientific World Journal
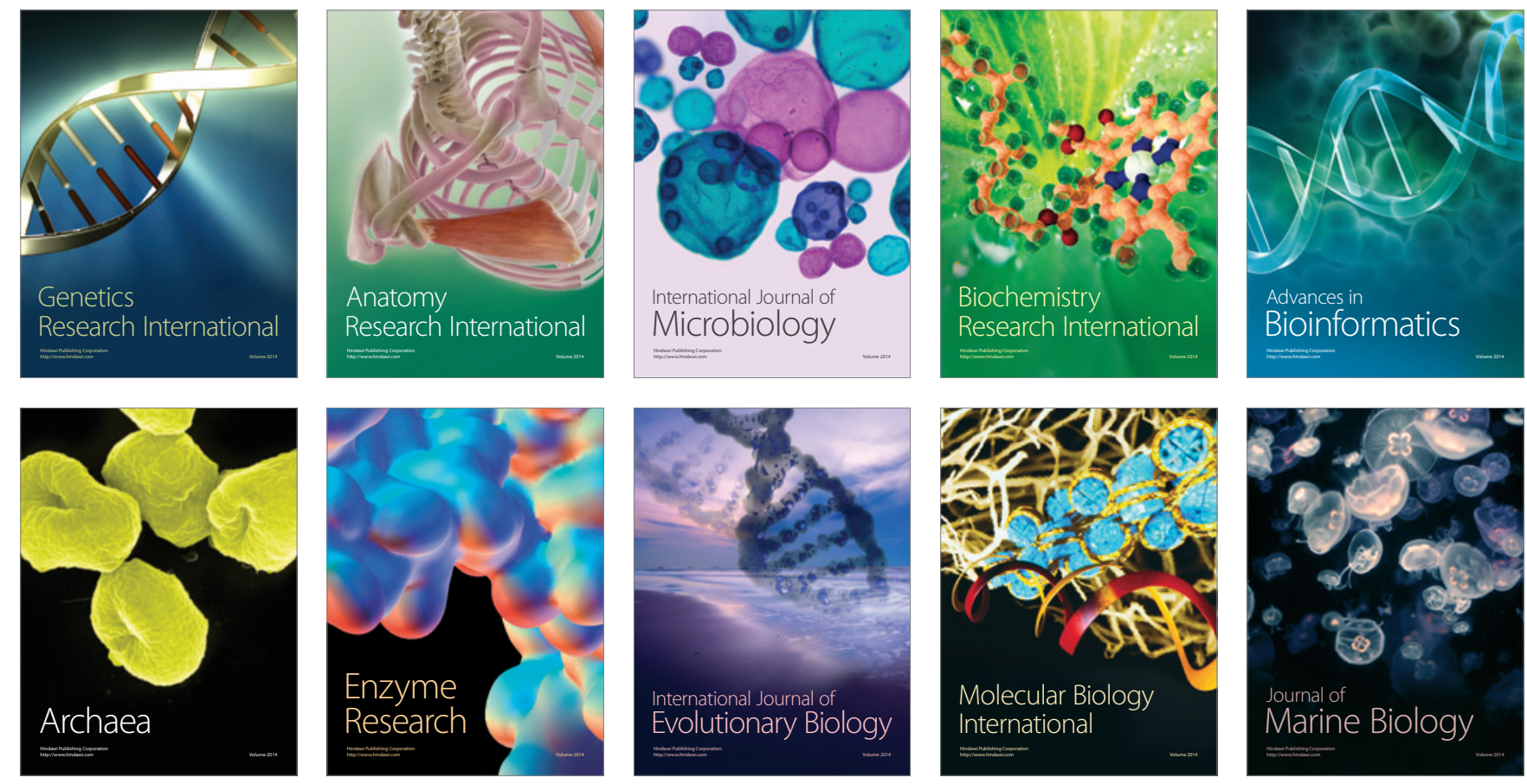